\title{
A OBRA “AS QUEIMADAS", DE ALFREDO ANDERSEN (1860-1935) E A REPRESENTAÇÃO DE IDENTIDADE NO PARANISMO
}

\author{
“AS QUEIMADAS” BY ALFREDO ANDERSEN (1860-1935) AND THE REPRESENTATION OF \\ IDENTITY IN PARANISM
}

\author{
Ana Lúcia Guimarães ${ }^{1}$ \\ Fausto Alencar Irschlinger ${ }^{2}$
}

${ }^{1}$ Acadêmica do $2^{\circ}$ ano do Curso de História da Unipar - Unidade de Cascavel; Acadêmica do PIC.

E-mail: anaguimaraes008@hotmail.com

${ }^{2}$ Professor e pesquisador do Curso de História da UNIPAR - Unidade de Cascavel.

E-mail: fausto@prof.unipar.br

GUIMARÃES, A. L.; IRSCHLINGER, F. A. A obra "As queimadas", de Alfredo Andersen (1860-1935) e a representação de identidade no paranismo. Akrópolis Umuarama, v. 25, n. 1, p. 3-12, jan./jun. 2017.

DOI: 10.25110/akropolis.v25i1.6669

Resumo: O Paranismo constitui-se como um movimento artístico e intelectual, que teve seu auge nas décadas 1920 e 1930, em regiões do Paraná. O presente trabalho busca analisar o movimento como parte da constituição identitária do estado, compreendendo-o como modelo instituído formalmente, advindo da necessidade de uma sintetização identitária pós-emancipação (1853), dotado de conotações políticas, que pertence, porém, a uma miríade constitutiva da identidade estadual, não sendo, desta forma, fator único desta. Buscando compreender de que forma o movimento interviu na construção e consolidação de símbolos e características identitárias do Paraná, utilizando-se de pesquisa bibliográfica sobre o tema e análise da representação empregada na obra "As queimadas [Lavadeiras]", de Alfredo Andersen. Assim, pretende-se averiguar de que forma a Arte inseriu-se no movimento e qual sua relevância na efetivação de seus objetivos.

PalaVras-chaVe: Brasil do século XX; Identidade; Paranismo; Representação.

ABSTRACT: Paranism is an artistic and intellectual movement that had its peak in the 1920s and 1930s, in regions of the state of Paraná, in Brazil. This work seeks to analyze the movement as part of the identity constitution of the state, understanding it as a formally instituted model, arising from the need for a post-emancipation identity synthesis (1853), endowed with political connotations, which belong to a myriad constitutive of the state's identity, and thus, not being its unique factor. Seeking to understand how the movement intervened in the construction and consolidation of Paraná's identity symbols and characteristics, it used bibliographical research on the theme and the analysis of the representation used in the work "As queimadas [Lavadeiras]", by Alfredo Andersen. Thus, it sought to find out how Art inserted itself in the movement and what is its relevance in the accomplishment of its objectives.

KEYWORDS: $20^{\text {th }}$ century Brazil; Identity; Paranism; Representation. 


\section{INTRODUÇÃO}

O movimento paranista caracteriza-se, segundo Batistella (2012), como o resultado de um processo de formulação de uma autoimagem paranaense, baseada em movimentos intelectuais, artísticos e ideológicos iniciados pela emancipação do estado em 1853. Batistella (2012) destaca também que a tentativa de formulação de uma identidade regional não pode ser vista como isolada na realidade paranaense, uma vez que, no fim do século XIX e início do século $\mathrm{XX}$, os movimentos regionalistas e nacionalistas efervesceram no $\mathrm{Brasil}^{3}$, assumindo perspectivas e conotações políticas e ideológicas múltiplas, buscando a invenção de uma tradição. Por sua vez, Hobsbawn (1997) aponta a tradição inventada como um conjunto de práticas regularmente aceitas, sob uma natureza ritualística e simbólica, visando a inculcar valores e normas de comportamento por meio da repetição e continuação do passado.

Sendo o Paranismo um movimento que influenciou e utilizou-se da historiografia do estado para a consolidação de uma identidade idealizada, cabe destacar a ressalva feita por Pesavento (1990) ao tratar da História Regional, sendo esta a abordagem utilizada pelo movimento. A autora destaca o forte cunho ideológico contido nesta, afirmando sua pretensão de "preservação de uma estrutura econômica determinada, ligada aos interesses das classes dominantes, que não exercitam a hegemonia a nível nacional, mas sim localmente" (PESAVENTO, 1990, p. 72). Dessa forma, ao tratar o movimento paranista como regional, é necessário atentar-se ao seu envolvimento político, não o tomando como movimento neutro, mas sim engajado com a formulação de uma identidade específica para a sociedade paranaense. Este cunho ideológico perpassa não somente a historiografia paranista, atingindo também as demais esferas componentes do movimento, sendo assim, a Arte insere-se neste contexto.

Assim, ao tratar sobre as intencionalidades paranistas quanto à construção e solidificação de uma identidade, faz-se necessária a compreensão sobre este conceito. Na Psicologia e na Antropologia, na qual se originam os estudos em torno da identidade, esta é tida como "um sistema de representações que permite a

${ }^{3}$ Outros estados, a exemplo do Rio Grande do Sul, tiveram movimentos que objetivavam uma formulação identitária regional. construção do "eu", ou seja, que permite que o indivíduo se torne semelhante a si mesmo e diferente dos outros" (SILVA K.V.; SILVA M. H.,2009, p. 202). Nestes campos, a identidade pressupõe a existência de, no mínimo, dois grupos ou indivíduos, pois esta se baseia em comparações, sendo que sua definição depende da percepção do indivíduo ou do coletivo frente ao outro, das diferenças com este e das semelhanças entre os membros do mesmo grupo. Este posicionamento de busca pela sistematização de uma identidade a partir da colocação dos elementos comuns aos indivíduos de um mesmo grupo frente aos demais coletivos sociais é utilizado pelo movimento paranista em sua busca pela formulação e tentativa de consolidação de fatores identitários de homogeneização do povo paranaense frente ao povo brasileiro ou aos demais estados federativos.

Ao tratar sobre a construção da identidade, DaMatta (1986) formula um modelo sistemático de análise:

A construção de uma identidade social, então, como a construção de uma sociedade, é feita de afirmativas e de negativas diante de certas questões. Tome uma lista de tudo o que você considera importante — leis, idéias relativas a família, casamento e sexualidade; dinheiro; poder político; religião e moralidade; artes; comida e prazer em geral - e com ela você poderá saber quem é quem. (DAMATTA, 1986, p. 15).

Percebe-se que o autor parte da perspectiva de que a identidade é construída, primeiramente, em âmbito prático, no seio da sociedade, sem haver, necessariamente, uma sistematização explícita. Assim, as proposições teóricas acerca da identidade de um grupo e de sua construção, em teoria, baseiam-se nas práticas cotidianas, compondo de forma metódica um conjunto de elementos que expressam estes elementos identitários que caracterizam o coletivo social. Contudo, Hall (2009), em sua discussão sobre identidade, aponta que:

[...] as identidades não são nunca unificadas; que elas são, na modernidade tardia, cada vez mais fragmentadas e fraturadas; que elas não são, nunca, singulares, mas multiplamente construídas ao longo de discursos, práticas e posições que podem se cruzer ou ser antagônicos. As identidades estão su- 
jeitas a uma historização radical, estando constantemente em processo de mudança e transformação. (HALL, 2009, p. 108).

Percebe-se então que o intento paranista de sistematização de uma identidade paranaense esbarra nesta multiplicidade discursiva, incutida nos fatores identitários, assinalada por Hall (2009). Destaca-se ainda, a afirmação do autor quanto à utilização de recursos da história, da linguagem e da cultura para a formulação de uma identidade, retomando-se, desta forma, à tradição inventada. O autor ressalta, ainda, a "narrativização" do sujeito, utilizando-se de elementos ficcionais para a construção de um discurso identitário. Neste contexto, inserem-se os símbolos eleitos pelo Paranismo, apontados por Camargo (2007, p. 160) como elementos de "manutenção das formas tradicionais de hegemonia política, econômica e agora, também, cultural". Estes símbolos e, por conseguinte, discursos, são para ambos os autores permeados por relações de poder, que visam à perpetuação de determinados valores, e assim, a exclusão de outros. Portanto, o pinheiro, o pinhão, a gralha, a figura do semeador e os demais símbolos eleitos pelo Paranismo devem ser percebidos como expressões do poder de um grupo, instituídos de forma consciente e intencionada, não como elementos aleatórios do cotidiano popular.

\section{OS IDEAIS PARANISTAS E SEUS REFLEXOS NA REPRESENTAÇÃO ARTÍSTICA}

O Paranismo surge inicialmente, no âmbito dos estudos históricos, políticos e na literatura, atendendo a uma necessidade de sintetização identitária pós-emancipação, ocorrida em 1853. Contudo, Salturi (2009) destaca que o auge do movimento paranista ocorreu entre os anos de 1927 e 1930, considerando que neste momento o mesmo encontrava-se em "[...] um período em que seus ideais estavam organizados e institucionalizados em forma de práticas culturais." (SALTURI, 2009, p. 14-15). Tal afirmativa baseia-se na criação da revista llustração Paranaense como forma de veiculação pública dos temas e ideários do movimento. Ao tratar sobre a revista, observa-se que, apresar de seu curto período de circulação (1927-1931), o periódico foi "[...] fundamental para a consolidação do Paranismo no imaginário dos paranaenses". (BATISTLLA, 2012, p. 9). Sendo que o movi- mento passou a fazer parte de comemorações oficiais, com maior influência em Curitiba, onde se fundam monumentos sob sua influência e se notabiliza a atuação do mesmo (id. ibid.).

Outro periódico de destaque no momento é a Revista do Clube Curitibano, que segundo Camargo (2007), propagava ideias em torno do Instituto Histórico e Geográfico do Paraná (IHGPR). Desse modo, percebe-se que sua atuação influenciou de forma marcante a institucionalização do Paranismo em seu intento de construção de uma identidade paranaense. Quanto ao veio teórico que guiava as ideologias deste grupo, destaca-se que:

A euforia cientificista do início do século $X X$ mais as fontes metafísicas trazidas pelo Simbolismo desenham a face contraditória do movimento que, porém, não era um fenômeno isolado, pois dividia características com outros esforços modernistas europeus (CAMARGO, 2007, p. 69-70).

Percebe-se assim um processo de assimilação e adequação de modelos teóricos importados, buscando utilizá-los de forma a corroborar em seu processo de estabelecimento de uma identidade estadual. Neste sentido, nota-se a atuação do IHGPR em um mesmo sentido que seus congêneres em outros estados, ou seja, seu objetivo de "[...] definir as características regionais e, literalmente, construir a história local" (CAMARGO, 2007, p. 57). Assim, é possível observar que a identidade e a História que tentaram ser construídas para o Paraná pelo movimento baseavam-se na constituição étnica, climática e ambiental do estado, buscando, principalmente os elementos que as diferenciassem das características de outros espaços territoriais e sociais. Neste sentido, percebe-se a atuação fulcral de algumas figuras intelectuais como Romário Martins, pois, suas obras foram tidas à época como a história oficial do Paraná. (BATISTLLA, 2012). Destarte, observa-se a centralidade da elite intelectual em um processo de tentativa de construção identitária paranaense, percebida tanto na figura institucional do IHGPR e do Paranismo, como na participação de alguns indivíduos específicos.

Além da historiografia, outras áreas do conhecimento agiram em favor dos ideais paranistas, como é o caso da Arte. Segundo Salturi (2009), as artes se integram ao movimento em meados da década de 1920, aderindo e expres- 
sando em suas obras os ideais elaborados pelos intelectuais da época. Com a consolidação dessa apropriação artística dos fundamentos do Paranismo, a Arte passou a desempenhar um papel fundamental no movimento, considerando-se que, segundo Camargo (2007), desde o Império esta vinha sendo utilizada como meio de difusão massiva de ideários, constituindo-se como instrumento político.

Agindo não apenas nas Artes Plásticas, observa-se que "na música e no teatro, o Paranismo se manifestou em motivos musicais baseados em canções tradicionais ou em gêneros populares com textos exaltando temas locais nas composições." (SALTURI, 2009, p.14). Contudo, as produções de maior destaque encontram-se nas Artes Plásticas, sendo marcadas por "um viés simbolista e ligações com as artes aplicadas e o design". (CAMARGO, 2007, p. 70). Neste sentido, o Simbolismo caracteriza-se como um movimento parisiense, de estima dos jovens intelectuais curitibanos, que alegavam que a proximidade climática tornava propenso o surgimento de expressões do movimento no Paraná. Enquanto ideologia, o Simbolismo rompia com uma tradição clássica e racional, justificando teoricamente sua singularidade artística e social por estar desvinculada de uma antecedência histórica e política, em um momento onde se exaltavam determinismos e cientificismos (id. ibid.).

Observa-se ainda, em algumas obras paranistas o que Bueno (2009) identificou como:

[...] um retorno às obras já consagradas dentro da História da Arte, como uma apropriação de algo já inventado, onde as mesmas foram adornadas com elementos que seriam característicos do movimento, ou seja, com a pinha, o pinhão e o pinheiro. Os artistas assumem as condições locais caracterizando-as e tornando-as positivas. (BUENO, 2009, p.51).

Assim, considera-se certo conservadorismo do movimento, que buscou em um repertório já disponível uma adaptação ao regionalismo, mantendo-se em contato e formalizando uma tradição estabelecida, diferenciando-se assim, do contexto do restante do país, que buscava na radicalização estética uma representação nacionalista. Quanto à estilização de elementos como a pinha, o pinhão e o pinheiro, observa-se novamente um norteamento simbolista, pois se elaboraram mitos de origem, a partir de dados científicos e literários disponíveis para que se "[...] estabelecesse as diferenças com o resto do país e principalmente com a província originária". (CAMARGO, 2007, p. 71)

Esta regionalização baseada em uma estética tradicional relegou ao Paranismo um desvio de possíveis diálogos com movimentos modernistas, que se vislumbrava em outras regiões do Brasil ${ }^{4}$. Não se retira, contudo, o valor deste "mergulho regional" do movimento. Entretanto, observa-se que tal posicionamento "[...] deixou a desejar a inserção paranaense na modernidade plástica, se comparamos com os ideais dos intelectuais paulistas de 1922". (BUENO, 2009, p.51). A aproximação feita por Bueno (2009) baseia-se na temporalidade quase simultânea entre os mesmos, apontando, contudo, que o período onde se inserem não pode levar a uma conclusão de proximidade discursiva entre os movimentos. Assim, observa-se que o Movimento Pau-Brasil (1924), alocado em São Paulo, possuía um discurso renovador, enquanto o Paranismo constituía-se como primeiro passo para a criação de uma plástica local, de consciência nativista. Neste sentido, Bueno (2009) chama atenção para o equívoco de tentar reduzir ou exemplificar todo o modernismo brasileiro apenas com base na experiência paulista, pois concomitantemente outros movimentos artísticos e intelectuais se articulavam em outros lugares do Brasil.

Desta forma, Camargo (2007) destaca que o posicionamento artístico é perpassado por relações de poder e interesses, assim, percebe-se que o engajamento do Paranismo com o regionalismo e com cânones tradicionais, que ocasionaram o afastamento do movimento artístico paranaense do modernismo discutido em outras regiões do país no início do século XX, é influenciado por uma miríade de sentidos, interligando-se com os objetivos daqueles que detinham o poder intelectual da época, além de atrelar-se a um projeto identitário específico, pretendido pelo movimento para o estado.

\footnotetext{
${ }^{4}$ Ao realizar esta comparação entre o academicismo/conservadorismo da Arte paranista e a estilização vanguardista do modernismo da Semana de 1922, ver obras de Tarsila do Amaral, Anita Malfatti, Candido Portinari e outros expoente do movimento modernista do eixo Rio de Janeiro - São Paulo, que representavam a fauna, flora e população brasileira de forma estilizada, tanto em formas, quanto em cores.
} 
ALFREDO ANDERSEN E A OBRA "AS QUEIMADA [LAVADEIRAS]"

As artes passaram a integrar-se ao movimento paranista, como citado, por volta da década de 1920 e, dentre outras figuras de destaque no meio artístico, vale ressaltar a participação de Alfredo Andersen. Seu estilo pictórico expressa sua origem europeia, transparecendo influências impressionistas, como a pintura ao ar livre e a ênfase ao naturalismo. Além disso, Andersen destaca-se por influenciar não somente a estética do Paranismo, mas também por participar diretamente da consolidação da profissionalização artística no Paraná, tendo destaque especificamente na formação na área da pintura (SALTURI, 2009). Neste sentido, observa-se sua atuação na Escola Alemã e no Colégio Paranaense e, ainda, suas proposições à criação de uma Escola Oficial de Belas Artes e a efetivação de seu projeto de Escola Profissional de Desenho para Operários, em $1909^{5}$. Ao tratar sobre a relação de seu estilo pictórico como influência aos seus métodos de ensino, Bueno (2009), aponta para os reflexos do impressionismo para além da obra de Andersen:

[...] influenciado pelas idéias impressionistas em seu trabalho pictórico, o mestre incorporou também alguns de seus conceitos em sua atuação didática, como a ênfase no naturalismo, traduzida pela observação direta da natureza [...] As paisagens executadas ao ar livre, bem como os estudos de modelos vivos e de naturezas mortas expressavam esse objetivismo visual. (BUENO, 2009, p. 56).

O objetivismo visual citado pela autora é característica também do movimento impressionista, sendo utilizado como conceito que definia a capacidade do artista em traduzir ao espectador uma sensação visual imediata. Ao tratar de Alfredo Andersen, boa parte dos autores cita a introdução do objetivismo visual na pintura paranaense como um de seus grandes legados.

Considerando a variedade de obras produzidas por Alfredo Andersen e os objetivos que norteiam o presente trabalho, optou-se por realizar uma análise da obra "As queimadas [Lavadeiras]". Para tanto, considerou-se a obra de Arte como fonte de pesquisa histórica e, objeti-

\footnotetext{
${ }^{5}$ Informações disponíveis no portal virtual do Museu Alfredo Andersen. Disponível em: <http://www.maa.pr.gov.br/modules/conteudo/ conteudo.php?conteudo=18>. Acesso em: 05 jul. 2016.
}

vando uma análise sistemática desta, elegeu-se uma abordagem de interpretação baseada no roteiro sugerido por Ott (1997), assim, a figura em análise será descrita, analisada, interpretada e fundamentada ${ }^{6}$.

Além disso, as considerações acerca da obra em análise baseiam-se ainda no conceito de representação, compreendido por Pesavento (2012) como construções que "[...] fazem com que os homens percebam a realidade e pautem a sua existência. São matrizes geradoras de condutas e práticas sociais, dotadas de força integradora e coesiva, bem como explicativa do real." (PESAVENTO, 2012, p. 39). Neste sentido, destaca-se a representação não enquanto reflexo ou mimese do real, mas como uma construção a partir dele. Destarte, observa-se na representação uma necessidade de processos de "[...] percepção, identificação, reconhecimento, classificação, legitimação e exclusão.", pois as representações são dotadas e portadoras do simbólico, dizendo mais do que aquilo que mostram, sendo dotadas de sentidos ocultos "[...] que construídos social e historicamente, se internalizam no inconsciente coletivo e se apresentam como naturais, dispensando reflexão." (id. ibid. p. 41). Sendo assim, expõem-se que a imagem simbólica necessita ser decifrada, por meio do conhecimento de códigos de interpretação, que se revelam coerentes com base em sua construção histórica em um dado contexto no tempo. Assim, as análises e observações sobre a obra em estudo partem da relação desses processos com elementos sócio históricos e ideologias do movimento artístico e intelectual no qual se insere.

\footnotetext{
${ }^{6}$ Araujo e Oliveira (2013) sintetizam as ações definidas pelo roteiro de Ott da seguinte forma: descrever refere-se à descrição dos aspectos formais da imagem. Ao analisar o leitor deve perceber os conceitos formais da obra visual, como o artista organizou a sua composição visual. No passo seguinte, o leitor deve interpretar a obra visual, apontando que sentimentos lhe são trazidos, ideias ou sensações. E no último estágio sugerido, é ampliado ao leitor o conhecimento da obra visual por meio do contexto, da história da obra.
} 


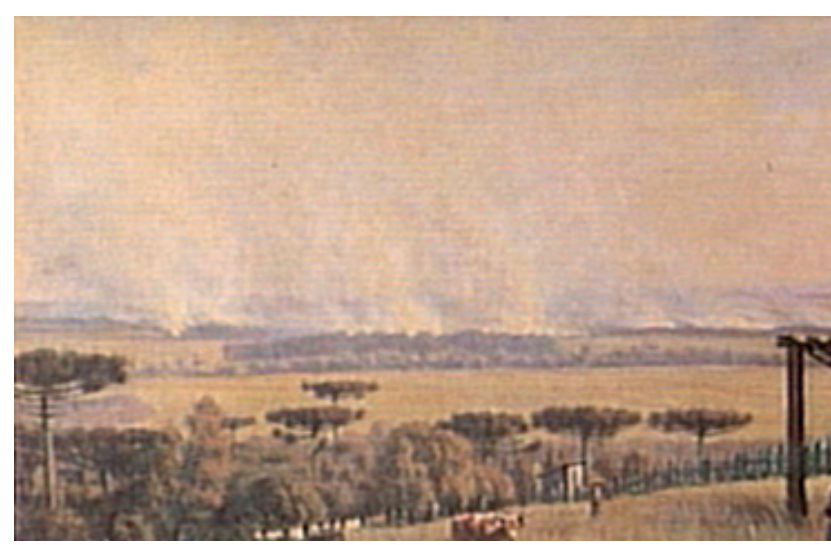

A Queimada [Lavadeiras] - Alfredo Andersen, s.d.

Óleo sobre tela, c.i.d. - 90,5 x $152 \mathrm{~cm}$

Disponível em: <http://www.itaucultural.org.

br/aplicExternas/enciclopedia_IC/index.

cfm?fuseaction $=$ obra\&cd_verbete $=998 \& c d$

obra $=8050>$ Acesso 13 jul. 2016.

A obra "As queimadas [Lavadeiras]" representa uma paisagem composta por áreas arborizadas e de pastagem, onde já houve o desmatamento. Ao fundo da obra vê-se o relevo com elevações e uma área encoberta por fumaça, que poderia representar uma prática comum do século $X I X$ e $X X$ de se realizar queimadas como forma de preparação do solo para o plantio. Mais a frente, são representados alguns bovinos, pastando em um ambiente delimitado por uma cerca de madeira e, próximo aos animais, há uma pequena construção em madeira, constituída apenas por pilares e telhado, debaixo da qual há duas mulheres. A figura em primeiro plano na obra também é uma mulher, que usa um vestido azul e chapéu, aparentando estar transportando algum tipo de cesto em seus braços. Ao chão a sua frente, vê-se roupas estendidas, possivelmente para quarar, alvejar. A composição é construída basicamente com cores frias e neutras, destacando-se os tons de verde, azul, ocre e marrom. O esquema cromático contribui para a criação de profundidade, em uso de técnicas de perspectiva na obra. As pinceladas apresentam-se rápidas, porém, pouco evidenciadas na composição. Observa-se claramente a tentativa de construção pictórica a partir da representação da incidência da luz solar sobre os elementos constituintes da paisagem.

Observando o momento histórico no qual Andersen se inseria (fim do século XIX, início do século $X X)$, é cabível apontar a influência de movimentos de pintores denominados por Gombrich (2015) como "revolucionários", expoentes no campo das Artes que viam a sociedade, as cores, formas e temáticas alteradas e influenciadas pelas "grandes Revoluções" do século $\mathrm{XIX}^{7}$. Considerando ainda que Andersen provinha da Europa, tendo sido radicado no Brasil em 1892 (BUENO, 2009), é possível observar a forte influência deste modelo europeu em sua obra. A temática de "As queimadas" expressa clara influência do movimento impressionista que pretendia a "abordagem direta da realidade, independente de qualquer poética previamente constituída" (ARGAN, 1992, p. 75). Cabe ainda a comparação a um artista precursor ao impressionismo, Jean-François Millet (1814-1875), especialmente, em sua obra "As respigadeiras" (1857), destacada como expressão de ruptura com o modelo acadêmico à medida que isenta as formas dos personagens de um romantismo utópico típico da academia da época, assumindo assim, "uma dignidade mais natural e mais convincente do que a dos heróis acadêmicos" (GOMBRICH, 2015, p. 511). Quanto às questões de técnica e cromática, "As lavadeiras" de Andersen assumem contornos pouco marcados, definidos apenas pela incidência e efeito da luz do sol em suas cores. Essa técnica de utilização da cor vista em plein air demonstra novamente a observação de Andersen ao estilo vanguardista que se projetava na Europa por meio da obra de Courbet, Monet, Manet e outros artistas chamados de impressionistas.

A opção de Andersen por um estilo pictórico inovador e de ruptura com a tradição apresentam alguns pontos de divergência, pois sua formação era de base acadêmica ${ }^{8}$, sendo destacada por Bueno (2009), sua associação ao academicismo feita pela literatura artística. Neste sentido, observa-se que sua prática torna acadêmico um estilo de origem revolucionária. Esta mescla de características de movimento e concepções diferenciadas presente na atuação de Andersen é perceptível também na configuração estética e discursiva do Paranismo como movimento, pois, segundo Camargo (2007), este atuou de forma a recombinar elementos românticos, acadêmicos, liberais e naturalistas, mantendo ainda característica do indigenismo. Deste modo, o autor afirma que:

[...] Este quase rompimento, apenas implícito e nunca assumido, será operacionalizado

${ }^{7}$ São citadas por Gombrich (2015) a Revolução Francesa, a Revolução Industrial e a Revolução de 1848.

${ }^{8}$ Bueno (2009, p. 56) destaca a "consistente formação na Academia de Belas Artes de Copenhague" de Andersen. 
para erigir uma formalização moderna que se diferenciasse da estética da capital do Império, e logo da República, mas mais ainda das formulações modernistas paulistas pós 1922. (CAMARGO, 2007, p. 75).

Destarte, observa-se novamente o posicionamento de diferenciação como base para a construção de uma identidade paranaense. Assim, retomando o exposto por DaMatta (1986), observa-se uma contraposição em um sentido comparativo a outros grupos - neste caso à província de São Paulo e ao restante do país - das características próprias do Paraná. Dessa forma, a utilização de uma configuração de modernidade diferenciada tinha por intuito manter esta singularidade.

Tal afirmativa exemplifica-se ao tratar sobre a obra "As queimadas", observando-se que a paisagem retratada esboça outro fator que salienta o envolvimento do artista com o Paranismo, além de explicitar algumas características do movimento, uma vez que a cena se passa em meio à flora típica do estado, exaltando um dos símbolos eleitos pelo Paranismo, o pinheiro. A paleta de cores utilizada na obra representa ainda um tipo de clima, também muito utilizado pelo movimento como forma de justificativa para "[...] o caráter pretensamente superior do paranaense, porque muito ameno e semelhante aos climas europeus, em contraste com a canícula tropical que impediria o desenvolvimento de uma civilização à européia." (CAMARGO, 2007, p. 26). Assim, elementos naturais como o clima e a flora receberam uma interpretação discursiva específica pelo movimento paranista, passando a ser resignificados, assumindo assim, um caráter cultural.

Para além da paisagem, o elemento humano representado na obra revela a perspectiva do movimento quanto ao povo paranaense, representado por mulheres que trabalham em um ambiente simples no campo, destacando a influência da agricultura e da pecuária para o Paraná. Tal afirmativa ancora-se na defesa por parte dos intelectuais paranistas da influência positiva do meio e de uma visão romântica e idealizada da mistura do "[...] europeu e do bom indígena que aqui vivia" (CAMARGO, 2007, p. 47). Neste sentido, ao tratar sobre o "tipo paranaense" eleito pelo Paranismo, destaca-se que a participação demográfica e econômica do escravo africano na constituição do estado é renegada, deste modo, tanto na historiografia oficializada que tem como expoente Romário Martins, como na Arte, a representação do negro é praticamente inexistente ${ }^{9}$ (id. ibid.).

Quanto à representação do imigrante europeu por parte do Paranismo, há ainda divergências no meio acadêmico, pois alguns autores apontam que este não ganha representatividade no movimento, ao considerar-se sua presença preocupante para a elite luso-brasileira, que temia a descaracterização do "tipo brasileiro"10. Contudo, não se pode negligenciar, que, inicialmente, a reflexão sobre a imigração é perpassada pela esperança idealizada do branqueamento atrelado a um ideal de civilização. Por sua vez, Camargo (2007) aponta para o posicionamento de ambos, imigrantes e nacionais, arraigado a seus costumes, portanto "na prática da convivência dos diferentes hábitos, e, cada vez mais, na competição pelo trabalho, o colono branco, redentor da raça, tinha seu estatuto de superioridade ameaçado pela banalização trazida pela convivência." (id. ibid., p. 62). Assim, a posição de recusa de submissão do elemento estrangeiro as formas de relação idealizadas pelos paranaenses e sua consequente atuação social ampliada, fez com que o Paranismo tornasse diminuta sua representação.

Em divergência a esse posicionamento, há autores que consideram que "uma das características do discurso dos idealizadores do Movimento Paranista (Romário Martins e Brasil Pinheiro Machado) era de integrar todos os indivíduos que adotassem o Paraná como a sua terra." (BUENO, 2009, p. 33). Este intento teria sido desarticulado pelo discurso xenofóbico de alguns intelectuais, defensores de que o movimento não partilhava de tal posição, afirmando sua abertura a todos os que tinham "afeição sincera" ao Paraná e defesa dos imigrantes.

Ao observar a obra de Andersen, não é possível definir características físicas específicas de algum grupo étnico. Contudo, percebe-se que as roupas utilizadas pelas mulheres que são representadas demonstram elementos correlacionais a vestimentas europeias do período, tratando-se talvez de imigrantes ou de descendentes de imigrantes. Em outra hipótese, pode-

\footnotetext{
${ }^{9}$ Destaca-se que a obra em análise não permite a observação da etnia das mulheres representadas. Neste sentido, as discussões propostas sobre o tema referem-se a uma representação adotada pelo movimento como um todo.

${ }^{10}$ Tal posicionamento tem como precursor o ícone da historiografia paranaense, Ruy Wachowicz, em obras como História do Paraná.
} 
-se considerar a apropriação de características culturais europeias, como o vestuário ${ }^{11}$, pela população que vivia no Paraná, deste modo, retoma-se à teoria de Hobsbawn (1997), ao tratar a tradição inventada como um comportamento ritualizado, que passa a ser naturalizado e tratado como inerente àquele grupo. Assim, mesmo que não representando explicitamente características europeias, percebe-se que peremptoriamente há uma apropriação destes elementos.

Neste caso, a imagem como elemento de representação simbólica se exemplifica ao considerar-se que "a força da representação se dá pela sua capacidade de mobilização e de produzir reconhecimento e legitimidade social. As representações se inserem em regimes de verossimilhança e de credibilidade, e não de veracidade." (PESAVENTO, 2012, p. 41). Desse modo, é possível observar, a exemplo da obra "As queimadas", a imagem e a Arte como instrumentos da tentativa de concretização de um ideal identitário paranista à medida que se percebe a busca por gerar uma identificação do espectador com a figura representada, utilizando-se de elementos genéricos da tradição inventada, como o vestuário, a atividade e o cenário no qual se constrói a cena.

Para além da questão étnica, percebe-se que a ideia de um indivíduo laborioso caracteriza-se como parte da representação paranista para o tipo paranaense, a exemplo da representação do trabalho na obra de Alfredo Andersen - em análise - e em outras obras do movimento como "O semeador" de João Zaco Paraná (1925) e inúmeras obras de Poty Lazarotto (1924-1998). Deste modo, ao tratar sobre o tipo paranaense eleito pelo Paranismo e sobre a característica do movimento de busca por diferenciar-se do restante do país, observa-se que:

Os escritores brasileiros do final do século XIX, como se viu, apoiaram-se na temática do meio e da raça como fatores explicativos unidade da nova nação. Já os paranaenses utilizam as mesmas idéias para, ao contrário, construir sua especificidade em relação à nação. Igualmente como já vimos, a questão das raças formadoras do povo brasileiro também receberá atenções especiais, mas no caso dos simbolistas paranaenses, a particu-

\footnotetext{
${ }^{11}$ Os animais representados próximos às mulheres reforçam a referência a características europeias, uma vez que não há espécies bovinas nativas da América. A inserção do gado no continente se deu por meio de expedições vindas da Europa.
}

laridade é a ênfase positiva sobre a figura do caboclo, resultado da mistura do português de do índio. (CAMARGO, 2007, p. 78).

Assim reforça-se que a ideia de que, tanto em um sentido ideológico, quanto em suas representações artísticas, o Paranismo busca a construção da identidade paranaense e de sua representatividade enquanto movimento a partir de um afastamento das práticas que se constituíam em nível nacional ou em outros estados. Ademais, percebe-se que as figuras, símbolos e sentidos escolhidos pelo mesmo não podem ser interpretados como aleatórios ou desprovidos de uma intencionalidade, pelo contrário, observa-se, ao analisar suas características como um todo e, especialmente, a obra estuda$\mathrm{da}$, que os sentidos propostos por tais elementos fundamentam-se em ideologias e na busca pela construção de uma identidade específica, retomando-se a ideia de que este constructo tem por intuito a perpetuação e legitimação de uma cultura específica, caracterizada assim, como dominante.

\section{CONSIDERAÇÕES FINAIS}

Ao tratar sobre o Paranismo como um movimento regionalista, que teve seu auge no primeiro quartel do século XX, observa-se o intento de formulação identitária paranaense a partir de uma ideia de diferenciação e busca por singularidades diante dos demais estados e da própria nação. Quanto aos dispositivos utilizados para a propagação de suas ideias, percebe-se o uso da historiografia, na figura de IHGPR e de Romário Martins, contando ainda com representações artísticas e monumentais de elementos simbólicos eleitos e mitificados pelo movimento, além de um determinado tipo de indivíduo paranaense.

Neste contexto, Alfredo Andersen inscreve-se como nome de destaque, por contribuir para o discurso visual paranista tanto com suas obras, como ao ministrar tal estilo em seu ateliê e escolas de Artes, contribuindo assim, para a formação artística e, principalmente pictural de diversos jovens artistas paranaenses, sendo que alguns ingressaram também no movimento. Já a obra escolhida para estudo - "As Queimadas [Lavadeiras]" - permite analisar e exemplificar elementos eleitos pelo discurso paranista, além de denotar, por meio de características técnicas 
(como estilo pictórico e temática), ideais e concepções teóricas do movimento, corporificadas, destacadamente, pelo Simbolismo. Percebe-se assim, que os elementos da obra unem-se para a expressão dos ideais e modelos eleitos pelos integrantes do movimento paranista, evidenciando a relevância da Arte na propagação e consolidação no imaginário coletivo do modelo identitário formulado pelo movimento.

Contudo, percebe-se que o movimento paranista caracteriza-se como uma parte dos elementos que influenciaram a construção de uma identidade paranaense formal, pois percebe-se que os ideais do movimento concretizam-se de forma mais marcante em âmbito teórico, expressando-se principalmente na capital do estado do que na realidade cotidiana da população em geral, que se insere em um contexto de identidades múltiplas e hibridismos. Além disso, ao estudar o Paranismo, percebe-se que a construção identitária de uma população é influenciada por disputas sobre o poder simbólico em um campo de forças sociais, em que diversas ideologias - mais ou menos corporificadas - buscam sua consolidação por meio da legitimação de símbolos e características eleitas como fundamentais à cultura de determinado grupo. Desse modo, observa-se que a compreensão da identidade de um grupo social perpassa por uma miríade de fatores, não podendo reduzir-se apenas a um de seus elementos constitutivos.

As reflexões sobre o tema possibilitaram o vislumbre da possibilidade de pesquisas futuras em torno da temática, podendo haver inúmeros enfoques diferenciados, aprofundando-a ou alterando-a. Sendo possível analisá-la partindo, tanto do movimento paranista, como das obras de Alfredo Andersen, de outros artistas e intelectuais inseridos no mesmo, que se apresentam como um vasto objeto de pesquisa. Neste sentido, observa-se a História Regional como área de pesquisa de grande amplitude e relevância, havendo ainda a necessidades de estudos em seu entorno.

\section{REFERÊNCIAS}

ARAUJO, G. C.; OLIVEIRA, A. A. Sobre métodos de leitura de imagem no ensino da Arte Contemporânea. In: Imagens da Educação, v. 3, n. 2, p. 70-76, 2013. Disponível em: <periodicos.uem.br/ojs/index.php/ ImagensEduc/article/download/20238/pdf>
Acesso em: 12 jul. 2016.

ARGAN, G. C. Arte Moderna. Tradução de Denise Bottmann e Frederico Carotti. São Paulo: Companhia da Letras, 1992.

BATISTELLA, A. O Paranismo e a invenção da identidade paranaense. In: Revista Eletrônica História em Reflexão. Dourados, v. 6 n.11, jan/ jun 2012.

\section{BUENO, L. E. B. O Paranismo e as artes}

visuais. 2009. 173 f. Dissertação (Mestrado em Artes Visuais). Centro de Artes, Universidade do Estado de Santa Catarina, Florianópolis, 2009.

CAMARGO, G. L. V. de. Paranismo: arte, ideologia e relações sociais no Paraná 1853 - 1953. 215 f. Tese (Doutorado em História). Setor de Ciências Humanas, Letras e Artes, Universidade Federal do Paraná, Curitiba, 2007.

DAMATTA, R. O que faz do brasil, Brasil?. Rio de Janeiro: Rocco, 1986.

GOMBRICH, E. H. A história da arte. 16. ed. Tradução de Álvaro Cabral. Rio de Janeiro: LTC, 2015.

HALL, S. Quem precisa da identidade? In: SILVA, Tomaz Tadeu da (Org.). Identidade e diferença: a perspectiva dos estudos culturais. Trad. de Tomaz Tadeu da Silva. Petrópolis: Vozes, 2009, p. 103-133.

HOBSBAWM, E.; RANGER, T. A invenção das tradições. 2. ed. São Paulo: Paz e Terra, 1997.

OTT, R. W. Aprendendo a olhar: a educação orientada pelo objeto em museus e escolas. São Paulo: MAC, 1989.

. Ensinando crítica nos museus. In:

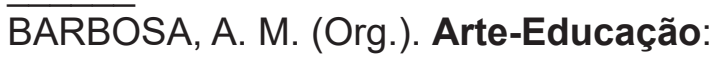
leitura no subsolo. São Paulo: Cortez, 1997.

PESAVENTO, S. J. História Regional e transformação social. In: SILVA, Marcos A. da. (Coord.). República em migalhas: História Regional e Local. São Paulo: Editora Marco Zero, 1990.

História e História Cultural. 3. ed. 
Belo Horizonte: Autêntica, 2012.

SALTURI, L. A. Paranismo, movimento artístico do sul do Brasil no início do século $X X$. In: Revista de recerca i informació en antropologia. n. 11, dez. 2009.

SILVA, K. V.; SILVA, M. H. Dicionário de conceitos históricos. 2. ed. São Paulo : Contexto, 2009.

\section{LA OBRA "LAS QUEMADAS", DE ALFREDO ANDERSEN (1860-1935) Y LA REPRESENTACIÓN DE IDENTIDAD EN EL PARANISMO}

Resumen: El Paranismo se constituye como un movimiento artístico e intelectual, que tuvo su auge en las décadas 1920 y 1930, en regiones del Paraná. EI presente trabajo busca analizar el movimiento como parte de la constitución identitaria del estado, comprendiéndolo como modelo instituido formalmente, surgiendo de la necesidad de una sintetización identitaria post emancipación (1853), dotado de connotaciones políticas, que pertenece, sin embargo, a una miríada Constitutiva de la identidad estadual, no siendo, de esta forma, factor único de ésta. En el caso de las mujeres, el número de mujeres en edad fértil es mayor que el de las mujeres. Así, se pretende averiguar de qué forma el Arte se inserta en el movimiento y cuál es su relevancia en la efectividad de sus objetivos.

Palabras clave: Brasil del siglo XX; Identidad; Paranismo; Representación. 